\title{
Research of Methods for Determining the Strength of Subgrade of Road Pavement
}

\author{
Lina Bertulienè \\ Vilnius Gediminas Technical University, Saulètekio al. 11, 10223 Vilnius, Lithuania
}

\begin{abstract}
Pavement structural strength is one of the main indices to determine pavement ability to carry traffic loads. The strength of separate layers of flexible pavement structures and of the whole pavement structure can be calculated during their design. It is very important and necessary to control whether, the strength of the newly built structural layers corresponds to their design strength in road construction and reconstruction. For this purpose, various methods for determining pavement structural strength are used. This article studies methods for determining structural pavement strength, assesses the strength measuring devices using static and dynamic methods. In order to identify and compare the accuracy of test data collected by using static and dynamic methods the comparative measurements were carried out on a base course of experimental road section by four measuring devices. Further results of the research of these results will enable to select the most suitable measuring method. Statistical analysis and assessment of research results obtained on the subgrade of road pavement.
\end{abstract}

Keywords: road pavement; measuring methods; traffic loads; pavement strength; subgrade.

\section{Introduction}

Road pavement is one of the most important structural elements of road. It is continuously affected by static and dynamic traffic loads, as well as climate change. Due to the impact of traffic and climate the physical and mechanical properties of subgrade soils and materials of structural pavement layers are changing. Critical conditions are created in winter and spring when, under the influence of cold, pavement materials become fragile and with a thawing ground they get to plastic due to excessive moisture. Unfavorable situation is caused in spring when separate structural pavement layers still contain excessive moisture, and asphalt pavement warms up under high temperatures. Therefore, the subgrade soils and structural pavement layers undergo deformation and their strength decreases.

The quality of road pavement, designed according to the highest technical standards and laid using advanced technologies, has been gradually changing: its service properties worsens, various defects appear and develop, pavement strength becomes insufficient. Due to the impact of traffic and climate it is necessary to determine structural condition of the road pavement and to select a strategy for pavement strengthening.

Most European countries use analytical methods for pavement design and determination of the need for pavement strengthening which conceptually are very similar. All the European and worldwide design methods are adjusted to the local climatic factors and materials used in that country. When using pavement strength determination models of other countries it is essential to adjust them to the particular country.

At present Lithuania uses different methodologies for the design of road pavements: the American AASHTO methodology as well as the pavement design methodology developed by DORNII on a basis of the Russian Road Instruction VSN 46-83.

The scientists of foreign countries use to determine the performance of pavement structure under real conditions by building and testing pavement structures in special test polygons. One of the largest test polygons was established in 1989, in the French Central Laboratory of Roads and Bridges. Here the scientists of various European countries tested and evaluated the performance of three different pavement structures. The pavement structures were tested under the effect of different loads, the readings of the transducers of stresses, pressure, temperature and moisture were recorded and the tendencies for the development of defects in the upper pavement layers were determined.

Corresponding author: Lina Bertulienė. E-mail address: lina.bertuliene@vgtu.lt

http://dx.doi.org/10.3846/enviro.2014.144

(C) 2014 The Authors. Published by VGTU Press. This is an open-access article distributed under the terms of the Creative Commons Attribution License, which permits unrestricted use, distribution, and reproduction in any medium, provided the original author and source are credited. 
In 2006-2007 the testing of road pavement structures by six different transducers was carried out in the University of Maine [1]. Transducers were installed in different pavement structural layers to determine seasonal effect on the structural strength of road pavement.

Models of the performance of pavement structure under real conditions have been comprehensively analyzed by the Professor of the Technical University of Denmark P. Ullidtz [2]. The scientist studies elasticity of pavement structure, distribution of stresses, models influencing the service life of road pavement, its condition and tendencies for the initiation and development of defects.

Šiaudinis [3] stated that Falling Weight Deflectometer is suitable to determine the structural strength of investigated road pavements and FWD measured results are close to results from measurements with static testing device. After range of experimental research the seasonal factors for measurements with FWD for Lithuanian conditions were determined [4]. Talvik and Aavik [5] founded good relationship between equivalent E modulus measured with FWD and road pavement structure layers indicators. Relationship between measured E modulus and subgrade indicators was founded not very strong.

More research relative with evaluation of correlation of measuring methods for road pavement structure layers were done in last decade [6-10].

This article gives the initial results of structural investigations of experimental road section, consisting of 27 different pavement structures. Further research results, their analysis and assessment will allow to select the most suitable measuring method for the separate pavement structural layers. A separate chapter describes methods for measuring structural pavement strength on the selected experimental road section with the use of four measuring devices.

\section{Static and dynamic methods for measuring strength}

Structural pavement strength is one of the main indices describing pavement ability to carry traffic loads. The strength of separate layers of flexible pavement structures and of the total structure of road pavement can be calculated during their design. Building and reconstructing roads is necessary to periodically control whether the strength of the newly built structural layers corresponds to their design strength. For this purpose various methods are used to determine the strength of structural pavement layers. From the recently worldwide used methods for determining road pavement strength the most effective method is based on deflection measurements (Fig. 1). The static and dynamic non-destructive methods are worldwide used to determine the deformation modulus of pavement structures, however, in many countries when designing and constructing road pavement structures their strength is defined by a static deformation modulus.

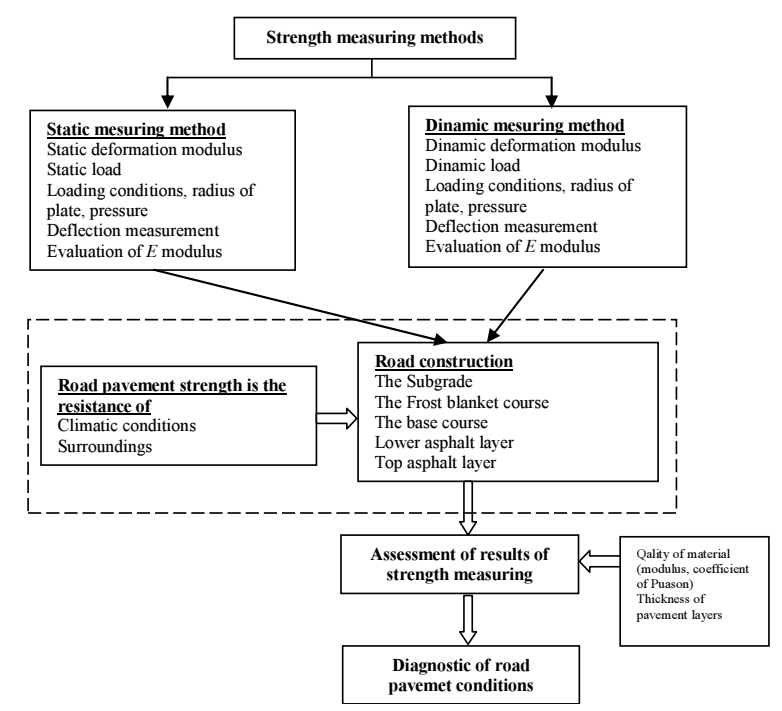

Fig. 1. Strength measuring methods based on deflection measurements [11]

In practice, the less complicated is a static strength measuring method. When using static measuring methods a certain area of road pavement structure is gradually loaded and unloaded. Generally, the following indices could be distinguished characterizing the static strength of road pavement, i.e. ability of the structure to resist: vertical stresses; horizontal stresses.

Ability to resist vertical stresses is expressed by the required modulus of elasticity; to resist horizontal stresses - by the quantity of permissible resistance to displacement. Comprehensive information about the static measuring method of strength could be given by a methodology aimed at a complex evaluation of all its components.

The essence of static methods for the evaluation of structural pavement strength is to create at road pavement surface a relative pressure which, according to its value, corresponds to the impact of load produced under the plate by vehicle wheel or dual wheels. In the first case the impact to the pavement surface is transferred through a rigid plate in an area which is equal to the calculated wheel track. Taking into consideration elastic deflection the total modulus of elasticity is calculated by the formula: 


$$
E=\frac{P \cdot D}{l}\left(1-v^{2}\right)
$$

where: $P$ - vehicle wheel pressure to the pavement, Pa; $D$ - diameter of the plate, $\mathrm{m}$; $l$ - forced inverse pavement deflection, $\mathrm{m} ; \boldsymbol{v}$ - Poisson's ratio.

In course of measurements and processing of test results one should take into consideration the effect of natural climatic factors. In this case a "typical condition of pavement structure" should be assumed described by the modulus of elasticity [12]:

$$
E=A-B\left(\lg \sum_{i=1}^{m} \frac{t_{E_{i}}}{10}-0.4\right),
$$

where: $A$ and $B$ - empirical coefficients depending on the type of road pavement structure, calculated load and climatic factors; $m$-number of measurements per year; $E_{i}$ - modulus of elasticity of road pavement structure in a reference point at a certain moment of time, $\mathrm{MPa} ; t_{E_{i}}$ - duration with $E_{i}$.

The above tests basically describe the average statistical modulus of elasticity of road pavement structure in a period of pavement service time. Based on investigation data it is only possible to evaluate pavement ability to resist main vertical stresses. This test does not allow to fully describe a condition of road pavement structure and to predict its further worsening.

A common disadvantage of all static methods is that when using these methods it is impossible to evaluate the ability of road structure to essentially realize a dynamic impact caused by a real traffic movement [13].

Static methods for calculating and evaluating road pavement strength are based on the maximum normal and tangent stresses. According to these criteria pavement failure takes place in a way of tear (according to maximum normal stresses) and shear (according to maximum tangent stress).

Generally, all the static calculation schemes and evaluation methods should be used to determine the structural pavement strength, ability of road structure to carry the significantly increasing traffic loads and, thus, to prevent the rapid failure of road structure. Based on the static strength results obtained with the help of dynamic coefficients and taking into consideration the rapidly increasing traffic flows and traffic loads - this is an empirical transition from static decisions of the theory of elasticity to the failure of insufficiently investigated road structures due to the impact of dynamic stresses. With the worsening pavement surface a dynamic impact of traffic is increasing. This is first of all showed by the increase in energy accepted by the road structure. Then, the tendency of changing relations between the different micro structural elements of road structure becomes obvious as well as of their failure.

In order to objectively evaluate road pavement condition it is suggested to use impact analogical to a real transport movement. Unlike the static measuring methods, dynamic methods make it possible to evaluate loads from moving transport.

When using dynamic measuring methods the load is produced by the drop of a falling massif cylinder in a very short period of time which causes deformations of structural pavement layers. Dynamic impact $Q_{d}$ and loading time $T_{f}$ are calculated by the approximation formulas [12]:

$$
\begin{gathered}
Q_{d}=M g \sqrt{\frac{2 H}{\delta}} k_{d}, \\
k_{d}=0,5\left(l+\frac{l^{\prime}}{l}\right), \\
T_{f}=\pi \sqrt{\frac{\delta}{g}} \cong 0,1 \sqrt{\delta},
\end{gathered}
$$

where: $M$ - mass of the falling weight, $\mathrm{kg} ; g$ - free acceleration of the falling weight, $\mathrm{m} / \mathrm{c}^{2} ; H$ - height of the falling weight, $\mathrm{cm} ; \delta$ - indicator defining a rigidity of suspension; $\mathrm{m} ; k_{d}$ - energy-loss coefficient of the falling weight; $l, l$ ' - vertical deformations from the drop of the first and the second falling weight, $\mathrm{cm}$.

Having made measurements with the use of dynamic measuring method the obtained elastic deflection is reduced to a comparative shape (static deflection) using coefficients of regression relationship [13]:

$$
l_{f}=X_{1} l_{d}+X_{2},
$$

where: $l_{f}$ - real deflection, $\mathrm{mm} ; l_{d}$ - deflection measured by a dynamic device, $\mathrm{mm} ; X_{1,2}-$ empirical coefficients of regression relationship.

The studded foreign methods and devices were based on the solutions of dynamic tasks and in the course of measurements and calculations the characteristics of road pavement deflections were taken into consideration. It should be noted that progressive equipment use a dynamic impact, whereas, the most expensive and most effective equipment are 
based on the impact data of a moving vehicle. The main disadvantages - a high price of equipment and serious technical difficulties related to the calibration of the measuring equipment.

The main advantage of dynamic methods is, by no means, their adequacy to real loads and traffic impacts. A wide experience of the use of dynamic analysis when testing road pavement proves a perspective development of these methods in the field of strength evaluation. The most informative is the analysis of the structural strength of dynamically loaded road pavement.

When determining the strength of different pavement structural layers by the static and dynamic measuring methods it was necessary to find out correlation between deformation modulus calculated from pavement structure deflections obtained by the static and dynamic devices.

Most of Lithuania's normative documents have been prepared according to the German normative documents and standards. At present based on LST 1360.5:1955 Road soils. Testing methods. Load test. 1995 Lithuania uses the recommended approximate values for reducing dynamic deformation modulus $E_{v d}$ to static deformation modulus $E_{2}$. Therefore, it is very important to justify the most suitable measuring method for the separate pavement structural layers and based on measuring results to suggest reduction coefficient values for each structural layer.

The values obtained by dynamic method would give an opportunity to carry out quality control and to assess the bearing capacity of the study layer not only by a static plate load test, which requires much time and efforts, but also by dynamic devices. A more wide use of the above mentioned dynamic devices would make it easier for the contractors, laboratories and engineers of road and railway construction enterprises to carry out a rapid and continuous quality control of embankments, roadbeds, soil layers and back-fillings [11].

\section{Construction of experimental road section}

In order to determine the strength of subgrade of experimental road section four different devices were used different in their measuring methodology and their operational principles. This article describes investigations carried out solely on the subgrade.

To determine the strength of subgrade (on the left side of the road) of the experimental road section four different devices were used: dynamic - FWD Dynatest 8000 (FWD), LWD Prima 100 (LWD) and ZORN ZSG 02 (ZORN); static - static beam (press) Strassentest (Static beam). On the right side of the road - FWD and static press Strassentest.

Measurements on each of the structural pavement layers were taken by the same selected scheme (location of a measuring point differs $\pm 0.5 \mathrm{~m}$ ) under the same weather conditions. Pavement deflections were measured by FWD Dynatest 8000 with $50 \mathrm{kN}$ load.

When laying subgrade for the experimental road section it was necessary to achieve the sufficiently equal subgrade strength, at least $100 \mathrm{MPa}$. The previously laid subgrade consisted of various building waste, the soil was heterogeneous. It was decided that the subgrade strength of more than $100 \mathrm{MPa}$ will have no large influence on the strength of all pavement structures as well as their operational indicators. The subgrade strength of more than $100 \mathrm{MPa}$ was achieved [14].

Investigations of the subgrade strength were carried out and the results were obtained using the static and dynamic measuring methods with four different measuring devices: dynamic - LWD Prima 100, FWD Dynatest 8000 and ZORN ZSG 02; static - static beam (press) Strassentest.

\section{Statistical analysis of investigation results on the subgrade}

Investigations showed a clear interrelation between the data obtained by static and dynamic devices. Analysis of measuring methods showed that there is a regular dependence between the static and dynamic methods.

The results in Fig. 2 and Fig. 3 show that the measuring data obtained by different measuring devices in different measuring points has a regular variation though their values differ. Taking into consideration small distances between measuring points it could be stated that the layer has not been evenly compacted, heterogeneous materials have been used for this layer or the measurement was taken not accurately.

The left side of the road section is affected by several times larger loads than the right side as this road leads to Pagiriai query.

To determine the reliability of results using the above methods the methods of mathematical statistics were applied. Having implemented the analysis and assessment of measurement data the reduction coefficient was suggested for the comparison of measuring results obtained on the pavement structural layers by the static and dynamic measuring methods.

When implementing research of experimental road sections for the analysis and assessment of the strength indices that were obtained the methods of mathematical statistics were used: descriptive statistics, analysis and interpretation methods. 


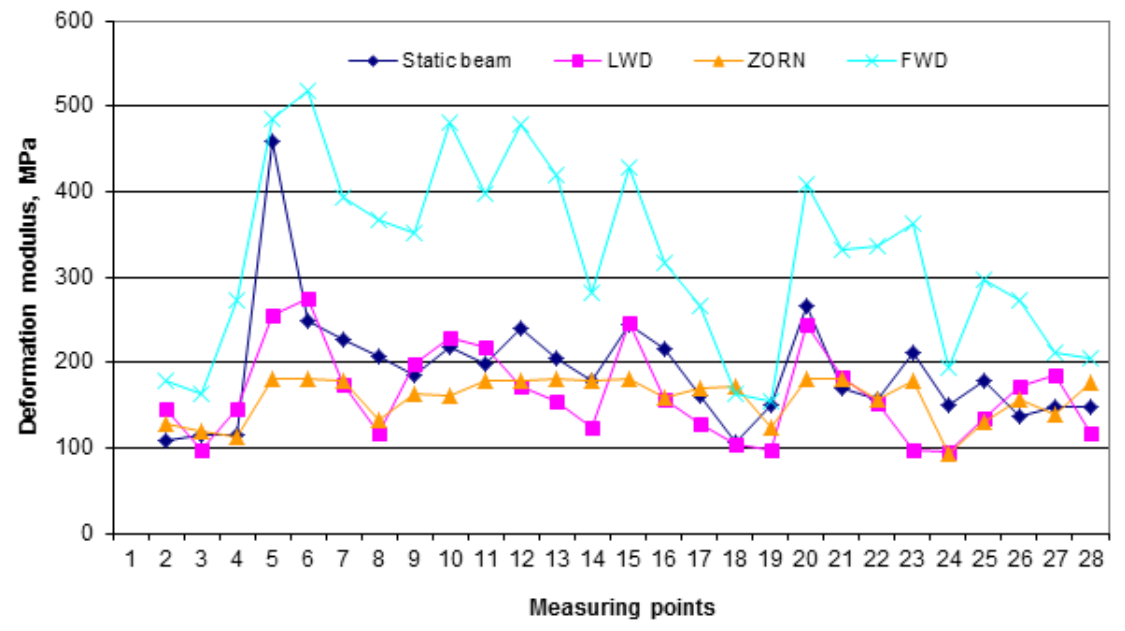

Fig. 2. Results of the subgrade strength measured by all the mentioned devices (left side)

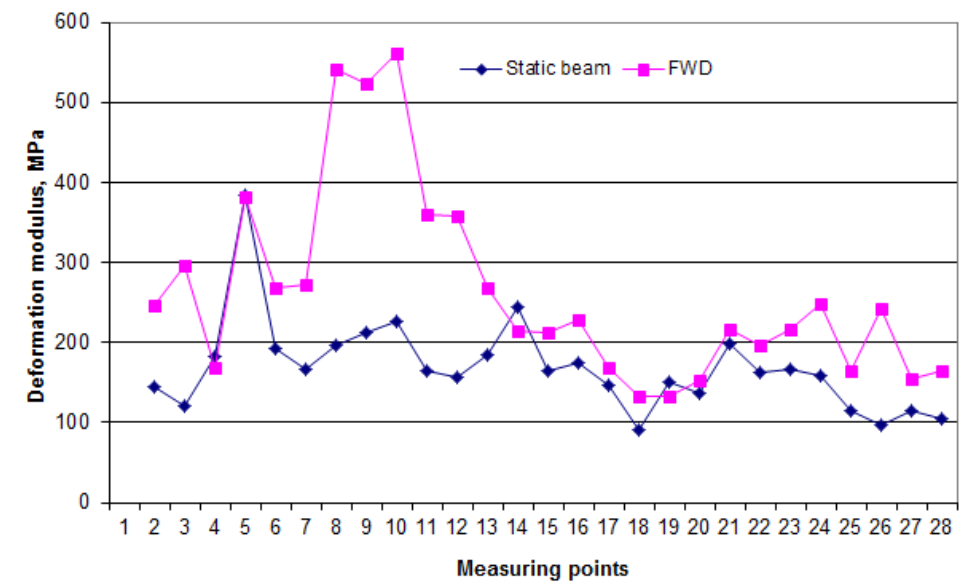

Fig. 3. Results of the subgrade strength measured by Static beam and FWD (right side)

A width of data set is defined as the difference between maximum and minimum values of statistical data.

Width is informative only in case where there are no exceptional values. A quartile width is most frequently used. It describes $50 \%$ dispersion of data values. A quartile width in statistics is represented by rectangular plots (Fig 4.). A rectangular plot shows a graphical min. $Q_{1}, M d, Q_{3}$ image.

Dispersion plots of results on the subgrade, frost-blanket course and pavement base showed a dispersion of results between each device. A large difference could be observed between minimum and maximum value. The lowest dispersion of results was indicated by the dynamic device ZORN and a Static beam and this shows more reliable measuring results. The highest dispersion of results was indicated by FWD.

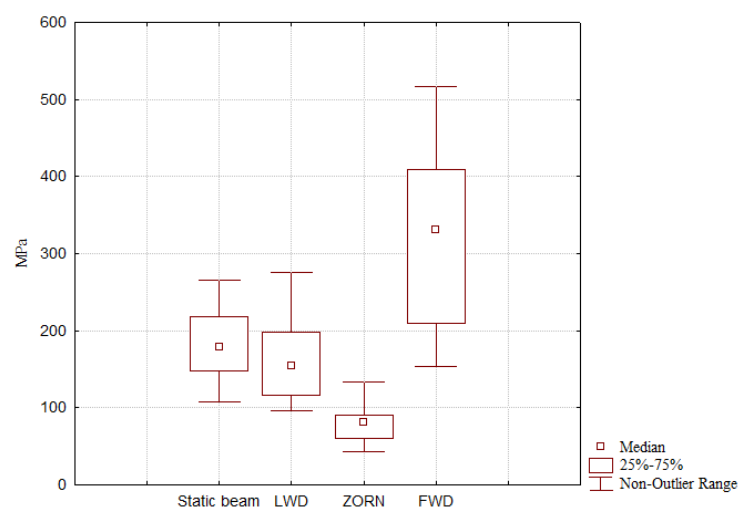

Fig. 4. Dispersion plot of measuring results on the subgrade (left side)

Correlation analysis. Correlation was obtained between the minimum and maximum different values of deformation modulus (Fig. 5). 


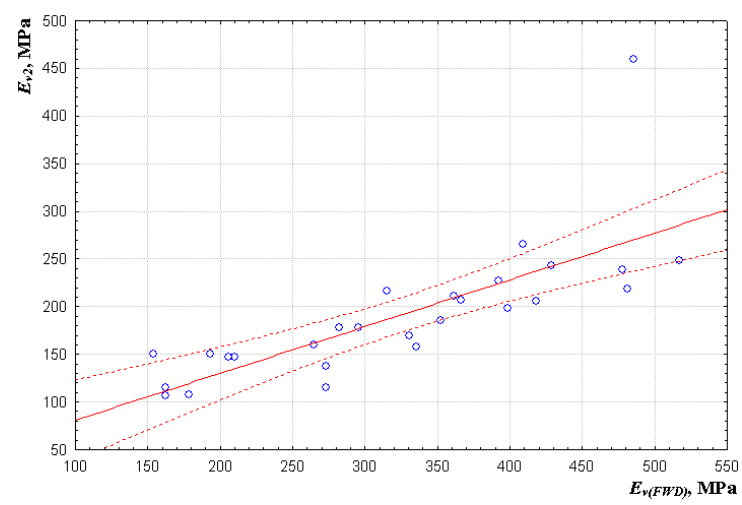

Fig. 5. Correlation between measuring results of the FWD and a Static beam on the subgrade of experimental road section in Pagiriai (left side)

The highest correlation was obtained when measuring deformation modulus on the subgrade on the left side by FWD and Static beam $\left(r^{2}=0.5853, r=0.7651\right)$, however, on the right side the correlation coefficient is not considerably lower $\left(r^{2}=0.2513, r=0.5013\right)$. Though the relationship between the static beam and other dynamic devices is not very strong this is explained by different methodologies.

Mathematical expression of the suggested reduction coefficient $k^{*}$ developed for the comparison of results obtained by the static and dynamic methods is as follows:

$$
k^{*}=\frac{E_{v 2}}{E_{v d}} \pm \Delta k
$$

When analysing measurements on the separate structural layers it was assumed that Poisson's ratio is constant, the effect of temperature was not considered (the effect of temperature must be considered when assessing strength measurements on asphalt layers).

The largest differences were obtained taking measurements by the FWD device, therefore, those measuring results will be discussed more widely. Reduction coefficient measured by FWD on the subgrade is 50\% higher than the normatyve.

\section{Conclusions}

Investigations were carried out and results were processed on the experimental road section of the Scientific Laboratory of Roads of the Vilnius Gediminas Technical University which was constructed in Pagiriai settlement. Measurements of the experimental road section were implemented using the static and dynamic measuring methods with the following measuring devices: static beam Strassentest, dynamic Falling Weight Deflectometer FWD Dynatest 8000, Light Weight Deflectometer LWD Prima 100 and dynamic device ZORN ZSG 02. It could be stated after the measurements that all the above devices are suitable for determining deformation moduli on the subgrade.

Analysis of measuring results of the subgrade obtained by dynamic devices shows that there is a regular correlation between all the devices, though, the numerical values of deformation modulus, compared to a static beam, vary: FWD Dynatest 8000 are by $70 \%$ higher, LWD Prima 100 and the dynamic device ZORN ZSG 02 are by $8-80 \%$ lower. Therefore, there is no possibility to unambiguously decide which method is the best and most acceptable.

The results of research of deformations of the structural layers of experimental pavement structures by the static and dynamic measuring devices showed that the structural strength of pavement layers determined by the Falling Weight Deflectometer is close to the strength determined by a static testing device. There is a linear relationship between the $\mathrm{E}$ modulus determined by the static and dynamic methods. Correlation of deformation moduli determined by different methods shows that the Falling Weigth Deflectometer can be used for determining the strength of investigated pavement structures using reduction coefficients developed by experimental research.

Having made the analysis and assessment of subgrade research results it could be stated that all measuring devices represent reliable results. Based on the analysis and assessment of research results for the reduction coefficient $k^{*}$ developed for the comparison of results obtained by the static and dynamic methods to use mathematical formula.

\section{References}

[1] Lauren, Y.; Swett, B. S. 2007. Seasonal variations of pavement layer moduli determined using situ measurements of pavement stress and strain. A thesis for the Degree of Master of Science. The University of Maine, May. 319 p.

[2] Ullidtz, P. 1998. Modeling Flexible Pavement Response and Performance. Denmark. 205 p.

[3] Šiaudinis, G. 2006. Relationship of Road Pavement Deformation Moduli, Determined by Different Methods, The Baltic Journal of Road and Bridge Engineering 1(2): 77-81.

[4] Šiaudinis, G.; Čygas, D. 2007. Determination of Seasonal Effects on the Structural Strength of Asphalt Pavements, The Baltic Journal of Road and Bridge Engineering 2(2): 67-72. 
[5] Talvik, O.; Aavik, A. 2009. Use of FWD Deflection Basin Parameters (SCI, BDI, BCI) for Pavement Condition Assessment, The Baltic Journal of Road and Bridge Engineering 4(4): 196-202. http://dx.doi.org/10.3846/1822-427X.2009.4.196-202

[6] Deblois, K.; Bilodeau, J. P.; Dore, G. 2010. Use of falling weight deflectometer time history data for the analysis of seasonal variation in pavement response, Canadian Journal of Civil Engineering 37(9): 1224-1231. http://dx.doi.org/10.1139/L10-069

[7] Yi, J. H.; Kim, Y. S.; Mun, S. H.; Kim, J. M. 2010. Evaluation of structural integrity of asphalt pavement system from FWD test data considering modeling errors, The Baltic Journal of Road and Bridge Engineering 5(1): 10-18. http://dx.doi.org/10.3846/bjrbe.2010.02

[8] Motiejūnas, A.; Paliukaite, M.; Vaitkus, A.; Čygas, D.; Laurinavičius, A. 2010. Research of Dependence of Asphalt Pavement Stiffness upon the Temperature of Pavement Layers, The Baltic Journal of Road and Bridge Engineering 5(1): 50-54. http://dx.doi.org/10.3846/bjrbe.2010.07

[9] Kavussi, A.; Rafiei, K.; Yasrobi, S. 2010. Evaluation of PFWD as Potential Quality Control Tool of Pavement Layers, Journal of Civil Engineering and Management 16(1): 123-129. http://dx.doi.org/10.3846/jcem.2010.11

[10] Tompai, Z. 2008. Conversion between Static and Dynamic Load Bearing Capacity Moduli and Introduction of Dynamic Target Values, Civil Engineering 52/2: 97-102. http://dx.doi.org/10.3311/pp.ci.2008-2.06

[11] Bertulienè, L. 2012. Assessment, Research and Use of Methods for Determining the Strength of Base Courses of Road Pavement Structure, The Baltic Journal of Road and Bridge Engineering 7(3): 228-236. http://dx.doi.org/10.3846/bjrbe.2012.31

[12] Оиенка прочности нежёстких дорожных одежд 218.1.052-2002 [Estimation of durability of nonrigid road clothes]. M.: Pocaвтодор, 2003 $79 \mathrm{c}$.

[13] Илиополов, С. К.; Селезнев, М. Г. 1997. Уточненный метод расчета напряженно-деформированного состояния системы “дорожная одежда-грунт" [The specified method of calculation of the is intense-deformed condition of system "road clothes - a ground"]. MП "Новая книга". Ростов-на-Дону, 1997. - 142 с.

[14] Bertulienė, L.; Laurinavičius, A. 2008. Research and Evaluation of Methods for Determining Deformation Modulus of Road Subgrade and Frost Blanket Course, The Baltic Journal of Road and Bridge Engineering 3(2): 71-76. http://dx.doi.org/10.3846/1822-427X.2008.3.71-76 